\title{
Assessing precipitation, evapotranspiration, and NDVI as controls of U.S. Great Plains plant production
}

\author{
Maosi Chen $10,1, \uparrow$ William J. Parton, ${ }^{1}$ Melannie D. Hartman, ${ }^{1}$ Stephen J. Del Grosso, ${ }^{2,3}$ \\ William K. Smith, ${ }^{4}$ Alan K. Knapp, ${ }^{5}$ Susan Lutz, ${ }^{2}$ Justin D. Derner, ${ }^{6}$ Compton J. Tucker, ${ }^{7}$ \\ Dennis S. Ojima, ${ }^{2}$ Jerry D. Volesky, ${ }^{8}$ Mitchell B. Stephenson, ${ }^{9}$ Walter H. Schacht, ${ }^{10}$ and Wei Gao ${ }^{1,11}$ \\ ${ }^{1}$ United States Department of Agriculture UV-B Monitoring and Research Program, Natural Resource Ecology Laboratory, Colorado State \\ University, Fort Collins, Colorado 80521 USA \\ ${ }^{2}$ Natural Resource Ecology Laboratory, Colorado State University, Fort Collins, Colorado 80523 USA \\ ${ }^{3}$ Agricultural Research Service, U.S. Department of Agriculture, Fort Collins, Colorado 80526 USA \\ ${ }^{4}$ School of Natural Resources and the Environment, University of Arizona, Tucson, Arizona 85721 USA \\ ${ }^{5}$ Department of Biology and Graduate Degree Program in Ecology, Colorado State University, Fort Collins, Colorado 80523 USA \\ ${ }^{6}$ Agricultural Research Service, U.S. Department of Agriculture, Cheyenne, Wyoming 82009 USA \\ ${ }^{7}$ Earth Resources Branch, NASA/Goddard Space Flight Center, Greenbelt, Maryland 20771 USA \\ ${ }^{8}$ Department of Agronomy and Horticulture, University of Nebraska-Lincoln, North Platte, Nebraska 69101 USA \\ ${ }^{9}$ Department of Agronomy and Horticulture, University of Nebraska-Lincoln, Scottsbluff, Nebraska 69361 USA \\ ${ }^{10}$ Department of Agronomy and Horticulture, University of Nebraska-Lincoln, Lincoln, Nebraska 68583 USA \\ ${ }^{11}$ Department of Ecosystem Science and Sustainability, Colorado State University, Fort Collins, Colorado 80523 USA
}

Citation: Chen, M., W. J. Parton, M. D. Hartman, S. J. Del Grosso, W. K. Smith, A. K. Knapp, S. Lutz, J. D. Derner, C. J. Tucker, D. S. Ojima, J. D. Volesky, M. B. Stephenson, W. H. Schacht, and W. Gao. 2019. Assessing precipitation, evapotranspiration, and NDVI as controls of U.S. Great Plains plant production. Ecosphere 10(10):e02889. 10.1002/ecs2. 2889

\begin{abstract}
Productivity throughout the North American Great Plains grasslands is generally considered to be water limited, with the strength of this limitation increasing as precipitation decreases. We hypothesize that cumulative actual evapotranspiration water loss (AET) from April to July is the precipitation-related variable most correlated to aboveground net primary production (ANPP) in the U.S. Great Plains (GP). We tested this by evaluating the relationship of ANPP to AET, precipitation, and plant transpiration (Tr). We used multi-year ANPP data from five sites ranging from semiarid grasslands in Colorado and Wyoming to mesic grasslands in Nebraska and Kansas, mean annual NRCS ANPP, and satellite-derived normalized difference vegetation index (NDVI) data. Results from the five sites showed that cumulative April-to-July AET, precipitation, and Tr were well correlated $\left(R^{2}: 0.54-0.70\right)$ to annual changes in ANPP for all but the wettest site. AET and Tr were better correlated to annual changes in ANPP compared to precipitation for the drier sites, and precipitation in August and September had little impact on productivity in drier sites. April-to-July cumulative precipitation was best correlated $\left(R^{2}=0.63\right)$ with interannual variability in ANPP in the most mesic site, while AET and Tr were poorly correlated with ANPP at this site. Cumulative growing season (May-to-September) NDVI (iNDVI) was strongly correlated with annual ANPP at the five sites $\left(R^{2}=0.90\right)$. Using iNDVI as a surrogate for ANPP, we found that county-level cumulative April-July AET was more strongly correlated to ANPP than precipitation for more than $80 \%$ of the GP counties, with precipitation tending to perform better in the eastern more mesic portion of the GP. Including the ratio of AET to potential evapotranspiration (PET) improved the correlation of AET to both iNDVI and mean county-level NRCS ANPP. Accounting for how different precipitation-related variables control ANPP (AET in drier portion, precipitation in wetter portion) provides opportunity to develop spatially explicit forecasting of ANPP across the GP for enhancing decision-making by land managers and use of grassland ANPP for biofuels.
\end{abstract}

Key words: aboveground net primary production; cumulative actual evapotranspiration water loss; cumulative growing season normalized difference vegetation index; North American Great Plains grasslands.

Received 23 February 2019; revised 7 May 2019; accepted 7 May 2019. Corresponding Editor: Debra P. C. Peters. 
Copyright: (C) 2019 The Authors. This is an open access article under the terms of the Creative Commons Attribution License, which permits use, distribution and reproduction in any medium, provided the original work is properly cited.

$\dagger$ E-mail: maosi.chen@colostate.edu

\section{INTRODUCTION}

Grassland and savanna ecosystems make up $>30 \%$ of the global land surface (Asner et al. 2004, Li et al. 2017). Grassland ecosystems store large amounts of carbon in soil organic matter and have a large impact on the interannual variations in net ecosystem carbon exchange (Zhang et al. 2010). Net primary production of grasslands is primarily controlled by precipitation, soil water content, and evapotranspiration, while other factors such as temperature and solar radiation have less direct impact on plant production (Parton et al. 2012, Mowll et al. 2015, Del Grosso et al. 2018). Numerous studies (Lauenroth 1979, Sala et al. 1988, Del Grosso et al. 2008) have shown that mean annual precipitation (MAP) is the major factor determining grassland aboveground net primary production (ANPP) with ANPP increasing linearly with increasing MAP at the site, regional, and global scales. Lauenroth and Sala (1992) have shown that ANPP increases linearly with increasing MAP at the site and regional levels for Great Plains (GP) grasslands; however, the slope of the change in annual ANPP with increasing precipitation at the site level is much lower than the slope for regional changes in mean ANPP with increasing MAP. In addition, sites with lower MAP tend to have steeper slopes than more mesic sites, suggesting that water limitations are strongest in drier grasslands.

Other climate-related variables, in addition to MAP, are also predictors of ANPP (Day et al. 1993, Lauenroth and Bradford 2006, Good et al. 2017). For example, Day et al. (1993) evaluated the correlation of nine different climate/weather variables with ANPP for grasslands in Australia. They found that transpiration and actual evapotranspiration (AET) were both highly correlated to ANPP $\left(R^{2}>0.70\right)$ and that the ratio of daily transpiration to vapor pressure deficit (VPD) had the highest correlation to observed ANPP. This suggests that ANPP is directly proportional to the amount of water passing through the plant and inversely proportional to the water loss rate.
Potential increases in air temperatures associated with climate change (IPCC 2013) have led to several studies evaluating the impact of air temperature on annual changes in ANPP (e.g., Epstein et al. 1997). More recently, Mowll et al. (2015) investigated the impact of temperature on grassland ANPP in the GP using ANPP data sets from semiarid grasslands along a latitudinal gradient. Their results showed that ANPP decreases slightly with increasing growing season mean temperature; however, the major factor that controlled annual changes in ANPP was precipitation. Similarly, Chen et al. (2017) found that including growing season temperature and potential evapotranspiration (or potential water loss [PET]) along with precipitation did not increase correlations with ANPP compared to precipitation alone for a grassland in Northeastern Colorado.

Although long-term ANPP measurements exist for a number of grassland sites across the North American GP (Petrie et al. 2018), remote sensing provides spatially extensive data for $>30$ yr. Satellite-derived normalized difference vegetation index or NDVI (Tucker 1979) measurements can be used to predict grassland daily to seasonal net carbon exchange and gross primary production (GPP) (Gilmanov et al. 2005, Morgan et al. 2016, Del Grosso et al. 2018). Gilmanov et al. (2005) developed a model to predict daily grassland GPP for different grasslands in the northern GP as a function of NDVI, solar radiation, VPD, and soil water content. Del Grosso et al. (2018) formulated regression models for predicting daytime net carbon and AET uptake as functions of NDVI and soil water content and showed that NDVI was strongly related to GPP. Integrated growing season NDVI is well correlated with ANPP (Paruelo et al. 1997, 2000, Irisarri et al. 2012, An et al. 2013, Hermance et al. 2015) or grassland live plant biomass (Parton et al. 2012), thereby providing spatially explicit ANPP estimates across the GP.

In this paper, we use different site-level and regional-scale data sets to investigate how precipitation-related variables and NDVI are related to spatial and temporal patterns of ANPP. The 
overarching goal of the analysis is to determine which precipitation-related variables (i.e., precipitation, $\mathrm{Tr}$, or AET) are primary predictors of ANPP across the semiarid (300-450 mm precipitation/yr) to mesic ( $>700 \mathrm{~mm}$ precipitation/yr) portions of the U.S. GP. We hypothesize that cumulative April-to-July AET will be the best predictor of ANPP in the GP as AET includes soil water storage from snow and rainfall during the prior fall and winter time periods as well as precipitation during spring and early summer growing season months. We also evaluated how strongly the ratio of precipitation to PET, the ratio of AET to PET, and other drought indices (e.g., Palmer drought severity index [PDSI]) are correlated to ANPP using site-level interannual ANPP and county-level mean annual NRCS ANPP data from the GP. Daily plant transpiration and AET rates were simulated by the DayCent model (Parton et al. 1998, Del Grosso et al. 2001, 2011). The AET results from DayCent model have been validated for several GP grassland sites (Parton et al. 1998, Chen et al. 2016, 2017).

A secondary goal of our analysis was to determine whether a general function could be derived that describes the relationship between mean ANPP and satellite-derived growing season (May-to-September) NDVI (iNDVI) for the entire GP. Whereas prior efforts (e.g., Paruelo et al. 1997, Chen et al. 2016) have focused at the individual site level, our efforts here were regionally specific with a focus on determining whether a differential relationship was observed in the correlation between ANPP and iNDVI between the northern and southern GP. Cool-season (C3) plants dominate in the northern GP; warm-season (C4) plants dominate in the southern GP. The correlations at both site and county levels were evaluated. At the site level, observed annual ANPP and iNDVI at five sites with different levels of precipitation (semiarid to mesic grasslands) were used to develop a general function between the two. At the county level, estimates of mean annual ANPP (2004-2014) derived from Natural Resources Conservation Service (NRCS) data sets (Sala et al. 1988) were used to determine the regional spatial patterns in ANPP and correlations of county-level iNDVI to precipitation-related controls. Because the county-level ANPP data are annual means and cannot be used to investigate the environmental controls on temporal variability within the growing season, we used county-level annual iNDVI data from 1982 to 2015 as a surrogate for ANPP.

\section{Methods}

\section{Descriptions of the five sites with long-term ANPP data}

Table 1 summarizes the basic information (i.e., location, climate, vegetation, and soil type) of the five GP sites.

The Central Plains Experimental Range (CPER) is a Long-Term Agroecosystem Research network site in northcentral Colorado (near $19 \mathrm{~km}$ northeast of Nunn). The site is typical of mid-continental semiarid grasslands with peak precipitation occurring during May and June (Chen et al. 2017). Central Plains Experimental Range has higher inter- and intra-annual variability than most forest sites (Knapp and Smith 2001). Central Plains Experimental Range has a winter (DJF) mean temperature of $-1.92^{\circ} \mathrm{C}$ and a summer (JJA) mean temperature of $19.76^{\circ} \mathrm{C}$ between 1912 and 2016. This shortgrass steppe site has a history (since 1939) of grazing by cattle during the growing season (mid-May to October) at a moderate stocking rate (Lauenroth et al. 1978). The plant production is mainly limited by water supply (Lauenroth et al. 1978).

The High Plains Grasslands Research Station (HPGRS) site is a northern mixed-grass prairie site located in southeastern Wyoming near Cheyenne (Zelikova et al. 2014). The precipitation at HPGRS peaks during April and May. High Plains Grasslands Research Station had a winter (DJF) mean temperature of $-2.21^{\circ} \mathrm{C}$ and a summer (JJA) mean temperature of $18.77^{\circ} \mathrm{C}$ between 1915 and 2016.

The Barta Brothers Ranch (BBR) site is located $11 \mathrm{~km}$ northwest of Rose, NE in Rock and Brown Counties, Nebraska. The BBR site is dominated by upland Sandhills prairie with scattered wetlands.

The Gudmundsen Sandhills Laboratory (GSL) site is located $8 \mathrm{~km}$ northeast of Whitman, Nebraska. About $80 \%$ of its precipitation occurs during the April through September growing season (Hendrickson et al. 2000).

The Konza Prairie (KNZ) is a Long-Term Ecological Research site located in the Flint Hills of 
Table 1. Basic location, climate, vegetation, and soil type information of the five Great Plains sites.

\begin{tabular}{|c|c|c|c|c|c|}
\hline Site & Location & $\begin{array}{l}\text { Mean annual } \\
\text { temperature } \\
\left({ }^{\circ} \mathrm{C}\right)\end{array}$ & $\begin{array}{l}\text { Mean annual } \\
\text { precipitation } \\
(\mathrm{cm})\end{array}$ & $\begin{array}{l}\text { Dominant vegetation cover and } \\
\text { plant species }\end{array}$ & Dominant soil type \\
\hline $\begin{array}{l}\text { Central Plains } \\
\text { Experimental } \\
\text { Range } \\
\text { (CPER) }\end{array}$ & $\begin{array}{l}40^{\circ} 49^{\prime} \mathrm{N} \\
104^{\circ} 46^{\prime} \mathrm{W} \\
1646.0 \mathrm{~m}\end{array}$ & 8.59 & 38.2 & $\begin{array}{l}\mathrm{C}_{4} \text { perennial shortgrass blue } \\
\text { grama (Bouteloua gracilis) with } \\
\text { some } \mathrm{C}_{3} \text { perennial graminoids } \\
\text { (western wheatgrass } \\
\text { [Pascopyrum smithii], needle } \\
\text { and thread [Hesperostipa } \\
\text { comata], and threadleaf sedge } \\
\text { [Carex eleocharis]) (Lauenroth } \\
\text { et al. 1978, Chen et al. 2017) }\end{array}$ & $\begin{array}{l}\text { Aridic Argiustolls and } \\
\text { Ustic Torriorthents } \\
\text { (Yonker et al. 1988) }\end{array}$ \\
\hline $\begin{array}{l}\text { High Plains } \\
\text { Grasslands } \\
\text { Research } \\
\text { Station } \\
\text { (HPGRS) }\end{array}$ & $\begin{array}{l}41^{\circ} 11^{\prime} \mathrm{N} \\
104^{\circ} 54^{\prime} \mathrm{W} \\
1920.2 \mathrm{~m}\end{array}$ & 7.66 & 45.8 & $\begin{array}{l}\text { Most of the vegetation is } \mathrm{C}_{3} \\
\text { graminoids, } \mathrm{C}_{4} \text { grasses make } \\
\text { up about } 25 \% \text { of the plant } \\
\text { community, and about } 20 \% \text { of } \\
\text { the plant community consists } \\
\text { of sedges, forbs, and small } \\
\text { shrubs (Zelikova et al. 2014) }\end{array}$ & $\begin{array}{l}\text { Fine-loamy, mixed, mesic } \\
\text { Aridic Argiusoll, pH } 7.9 \\
\text { (Zelikova et al. 2014) }\end{array}$ \\
\hline $\begin{array}{l}\text { Barta Brothers } \\
\text { Ranch (BBR) }\end{array}$ & $\begin{array}{l}42^{\circ} 14^{\prime} \mathrm{N} \\
99^{\circ} 39^{\prime} \mathrm{W}\end{array}$ & 9.10 & 50.8 & $\begin{array}{l}\text { Dominant warm-season } \\
\text { grasses: prairie sandreed } \\
\text { (Calamovilfa longifolia), sand } \\
\text { bluestem (Andropogon hallii), } \\
\text { little bluestem (Schizachyrium } \\
\text { scoparium), and switchgrass } \\
\text { (Panicum virgatum L.); } \\
\text { common cool-season species: } \\
\text { needle grasses (Stipa spp.) } \\
\text { (Schacht et al. 2000) }\end{array}$ & $\begin{array}{l}\text { Sandy soils. Soils of the } \\
\text { uplands are in the } \\
\text { Valentine series (mixed, } \\
\text { mesic Typic } \\
\text { Ustipsamments) (Schacht } \\
\text { et al. 2000). }\end{array}$ \\
\hline $\begin{array}{l}\text { Gudmundsen } \\
\text { Sandhills } \\
\text { Laboratory } \\
\text { (GSL) }\end{array}$ & $\begin{array}{l}42^{\circ} 07^{\prime} \mathrm{N} \\
101^{\circ} 43^{\prime} \mathrm{W}\end{array}$ & 8.33 & 44.8 & $\begin{array}{l}\text { Similar to BBR (Volesky et al. } \\
\text { 2005) }\end{array}$ & $\begin{array}{l}\text { Similar to BBR (Volesky } \\
\text { et al. 2005) }\end{array}$ \\
\hline $\begin{array}{l}\text { Konza Prairie } \\
\text { (KNZ) }\end{array}$ & $\begin{array}{l}39^{\circ} 05^{\prime} \mathrm{N} \\
96^{\circ} 35^{\prime} \mathrm{W}\end{array}$ & 12.5 & 83.8 & $\begin{array}{l}\text { Rhizomatous, C4 perennial } \\
\text { grass species (i.e., Andropogon } \\
\text { gerardii and Sorghastrum } \\
\text { nutans) (Wilcox et al. 2016) }\end{array}$ & $\begin{array}{l}\text { Silty clay loams (typical of } \\
\text { North American } \\
\text { grassland Mollisols) with } \\
\text { high concentrations of } \\
\text { organic carbon in the } \\
\text { surface A horizons } \\
\text { (Melzer et al. 2010) }\end{array}$ \\
\hline
\end{tabular}

northeastern Kansas (Wilcox et al. 2016). KNZ is a native tallgrass prairie. Most of its precipitation occurs during the growing season (Wilcox et al. 2016).

\section{ANPP data sets}

The 31-yr ANPP data at the CPER site from 1983 to 2014 were estimated from the observed live biomass levels of the five plant functional groups (i.e., Bouteloua spp, C3 annual grasses, C3 perennial grasses, $\mathrm{C} 4$ perennial grasses, and forbs and recent standing dead biomass) from clipped biomass plots (1.8- $\mathrm{m}^{2}$ quadrants) in four pastures (Midslope, Ridge, Owl Creek, and Swale). The data were collected at peak biomass, generally in late July or early August. The details of the CPER ANPP data are described in Lauenroth (2013).
The 35-yr ANPP data at HPGRS site from 1982 to 2016 were obtained by averaging peak standing crop (between the end of July and the end of August) from the moderate and heavy grazing treatments (Derner and Hart 2007). Biomass was hand clipped from $1.5-\mathrm{m}^{2}$ plots or derived from a capacitance meter reading (Derner and Hart 2007).

The ANPP data sets from BBR and GSL included annual estimates of peak standing crop from 1999 to 2015. Sampling methodology was the same for both BBR and GSL locations and included hand-clipping all vegetation to ground level in $0.25 \mathrm{~m}^{2}$ quadrats and sorted into plant functional groups of C4 grasses, C3 grasses, forbs, sedges, shrubs, and standing dead and litter (Volesky et al. 2005). Clipping was conducted in 
mid-August each year with a total of 60 quadrats clipped at the BBR location and 30 at GSL. Analysis of the ANPP, AET, and PET rates from the BBR and GSL sites showed that mean values were quite similar for both sites. Therefore, the observed ANPP and NDVI data sets from BBR and GSL sites were combined as the Nebraska (NEB) site in our correlations of environmental variables to iNDVI and ANPP. We excluded observed ANPP data from BBR from 2001 and 2002 and NDVI data from GSL from 2006 and 2012 from our statistical analysis because they were outliers relative to the observed data (Appendix S1).

The 35-yr ANPP data at KNZ site from 1982 to 2016 were obtained by clipping $200.1-\mathrm{m}^{2}$ plots between August and October. The details of the KNZ ANPP data are described in Wilcox et al. 2016, . The data from the KNZ site came from the upland site representing typical ANPP observed at the KNZ site located on more shallow, rocky soils (Knapp et al. 1998).

The decadal mean county-level NRCS ANPP observations were determined for each of the GP counties by averaging all the site-level ANPP values (the "estimated average production") within each county during 2004-2014 (g biomass $\cdot \mathrm{m}^{-2} \cdot \mathrm{yr}^{-1}$ ) (Appendix S2: Table S1) (USDA-NRCS 2018). The NRCS measures clipped plot ANPP for multiple locations within each county using a technique described by Sala et al. (1988). The ANPP county-level estimates were determined for 254 U.S. GP counties. All ANPP estimates $<10.0 \mathrm{~g}$ biomass $\cdot \mathrm{m}^{-2} \cdot \mathrm{yr}^{-1}$ and $>700 \mathrm{~g}$ biomass $\cdot \mathrm{m}^{-2} \cdot \mathrm{yr}^{-1}$ were excluded since those are unrealistically low or high ANPP values for the GP. We also excluded counties with mountainous terrain where NDVI signal may include trees as well as grasses. It is worth noting that NRCS ANPP data for GP counties were not used in the DayCent model tuning process. They are only used to compare with the NDVI data and to correlate with DayCent-simulated countylevel AET and other rain-related variables.

\section{NDVI data sets}

The Advanced Very High Resolution Radiometer (AVHRR) biweekly NDVI measurements (NOAA 1992) from multiple pixels around the CPER Pasture $24 \mathrm{SW}$ in Colorado (1-km pixels centered at $40.82^{\circ} \mathrm{N}, 104.73^{\circ} \mathrm{W}$ ) were averaged to represent the NDVI values at CPER site from 1982 to 2016. We averaged numerous pixels because the pasture was much larger than $1 \mathrm{~km}^{2}$. Following the procedure described in Chen et al. (2017), the NDVI base value $\left(\mathrm{NDVI}_{\text {base }}=0.20\right)$, typical of NDVI during the non-growing season (November to March), was subtracted from each biweekly value from May to September, and these values were accumulated to compute iNDVI (Eq. 1). AVHRR biweekly NDVI measurements around the HPGRS site is averaged from the $1-\mathrm{km}$ pixels centered at $41.22^{\circ} \mathrm{N}$ and $104.86^{\circ} \mathrm{W}$. For this site, we also computed iNDVI for years 1982-2016 using a base NDVI value of 0.20 .

$$
\mathrm{iNDVI}=\sum_{\mathrm{wk}=\text { May1 }}^{\text {Sep30 }}\left(\mathrm{NDVI}_{\mathrm{wk}}-\mathrm{NDVI}_{\mathrm{base}}\right) .
$$

The BBR and GSL sites are both located in Nebraska. Barta Brothers Ranch is situated in Rock and Brown counties, and GSL is located in Cherry, Grant, and Hooker counties. The specific site AVHRR NDVI data location for BBR is $42.23^{\circ} \mathrm{N}$ and $99.65^{\circ} \mathrm{W}$, while GSL is at $42.06^{\circ} \mathrm{N}$ and $101.52^{\circ} \mathrm{W}$. For these sites, we computed iNDVI using a NDVI base value of 0.22 . The time period for BBR is 1999 to 2015, and GSL is 2004 to 2015.

KNZ is located in the northeastern part of Kansas. For KNZ, the specific site location for the observed AVHRR NDVI data is $39.08^{\circ} \mathrm{N}$ and $96.56^{\circ} \mathrm{W}$. We calculated the iNDVI values using the base NDVI value of 0.28 . The time period for KNZ is 1984 to 2015.

For the regional analysis, we used third generation Global Inventory Modeling and Mapping Studies normalized difference vegetation index (NDVI3 g; Pinzon and Tucker 2014) data to calculate county-level bimonthly grassland iNDVI from 1982 to 2015. We removed all NDVI observations that were flagged as snow- or cloudcovered (Pinzon and Tucker 2014), to isolate grasslands. We excluded pixels identified as barren, forest, or crop using Moderate Resolution Imaging Spectroradiometer land cover data (Friedl et al. 2010). Like site-level iNDVI, countylevel iNDVI was also computed by subtracting base NDVI values (0.10 to 0.15 ). This iNDVI data set was then correlated to the mean annual county-level NRCS ANPP data (270 counties). 


\section{DayCent model description}

The long-term actual evapotranspiration (AET) and transpiration $(\mathrm{Tr})$ data are simulated using the DayCent model. DayCent is a biogeochemical model that simulates the fluxes of water, carbon, and nitrogen (or nutrients) among the atmosphere, plants, and soil in crop/grassland, forest, and savanna ecosystems (Parton et al. 1998, Del Grosso et al. 2001, 2011, Straube et al. 2018). The primary inputs to DayCent include site location, daily weather data (e.g., maximum and minimum temperature, precipitation, and solar radiation [optional]), soil texture and hydraulic properties, vegetation parameters, and land management practices (e.g., grazing intensity) (Chen et al. 2016, Del Grosso et al. 2016). The functionality of DayCent is implemented in four primary submodels: plant growth and production, soil decomposition, land surface, and trace gas fluxes (Del Grosso et al. 2001, 2011).

In DayCent, daily AET is simulated in its land surface submodel (Parton et al. 1998). The major factors, which control daily AET in the model, include the potential daily evapotranspiration rate (PET), live leaf biomass, and soil water content. More specifically, AET from two sources is simulated. First, water inputs (e.g., precipitation, irrigation, and snow melt) intercepted by plants and litter are evaporated at the rate of PET, where PET is calculated as a function of air temperature, latitude, and time of year (Parton et al. 1998). Then, remaining water either passes through soil layers as saturated or unsaturated flow, or goes to surface runoff (Parton et al. 1998). During these processes, if the water content in the first soil layer is higher than its minimum soil water content threshold, water is evaporated from this layer at the rate of PET (Parton et al. 1998). In addition, the transpiration at each soil layer is simulated as a function of plant live biomass and rooting depth (Parton et al. 1998). It is worth noting that the correlations of ANPP to AET are not connected to the way that AET is calculated. The well-calibrated DayCent model was used to estimate AET for all of the years when ANPP is observed. Previous work (Chen et al. 2016, 2017) has demonstrated that the DayCent-simulated AET agreed with the observations at CPER site from 1980s to early 2000s $\left(R^{2}=0.55,0.81\right.$, and 0.92 for daily, weekly, and monthly aggregations, respectively). Results in the online material (Appendix S3: Fig. S1-S3) show similar $R^{2}$ values for the comparison of eddy covariance observed AET from the KNZ site with the simulated AET and also show that there is little year to year variations in the seasonal patterns in AET at the KNZ site. Both model results and observed AET data from KNZ and CPER (Appendix S3: Figs. S1, S2) show that AET rates are low during the winter (because there is no transpiration and low PET), high during the summer (because PET and leaf area are high). Yearly differences in AET and soil water are primarily controlled by seasonal patterns in daily precipitation.

For both the site-level and the regional-level analyses, we used the DayCent model to simulate daily bare soil evaporation, Tr, interception of precipitation by vegetation, sublimation, runoff, and PET. AET was the sum of bare soil evaporation, $\mathrm{Tr}$, and interception. Site-level soils, vegetation, and weather data were used to drive the simulations for the 5 sites. For the regional analysis, we extracted relevant variables from DayCent simulations of native grassland conducted at the county level (1982-2016) for all of the GP counties described in Hartman et al. (2011) and Parton et al. (2015).

\section{Site-level and county-level analyses}

Yearly DayCent estimates of AET, transpiration, and PET were used to determine the correlation of site-level seasonal changes in ANPP for the CPER, HPGRS, BBR, GSL, and KNZ sites to cumulative (i.e., April-to-May, April-to-June, April-to-July, April-to-August, April-to-September, and annual sums of) precipitation, AET, and Tr using the long-term ANPP observations. We developed quadratic and linear regressions of yearly sitelevel ANPP to yearly iNDVI and the ratio of April-to-July AET to April-to-July PET from the same years. As part of our analysis, we also looked at the site-level correlation of the April-toJuly Palmer drought severity index (PDSI) (Dai 2017) to ANPP for the five sites.

For the county-level analyses, we quantified the correlation between iNDVI and ANPP by comparing mean annual 1982-2015 iNDVI to mean annual 2004-2014 NRCS ANPP. We used DayCent estimates of mean (1982-2015) April-to-July and mean annual total AET, precipitation, and PET to determine the correlations precipitation-related 
variables (AET and precipitation) and drought indices (AET/PET, PPT/PET) to NRCS mean (2004-2014) county-level ANPP. We also correlated yearly (1982-2015) values of April-to-July AET and April-to-July AET/PET to yearly (1982-2015) AVHRR cumulative May-to-September NDVI (iNDVI).

\section{RESULTS}

We first compared mean annual ANPP, precipitation-related variables (annual average precipitation, sublimation, transpiration water loss, runoff, bare soil evaporation water loss, and interception water loss) along with their percentages of precipitation for the five long-term ANPP sites along the precipitation gradient (Table 2). As expected, mean ANPP generally increased with increasing MAP and transpiration water loss, and decreasing aridity index (i.e., PET/PPT). The absolute amount of water loss from transpiration increased with increasing annual precipitation, while the bare soil evaporation and plant interception water loss were similar for all of the sites with the fraction of water loss from evaporation (bare soil water loss plus plant interception) decreasing with increasing precipitation and decreasing aridity index $(43 \%$ [32.8 $+10.5 \%]$ for CPER vs. $23 \%[16.8+6.0 \%]$ for KNZ). The relative amount of annual precipitation lost as transpiration was similar for all of the sites $(45 \%$ to $47 \%$ ) while as expected the fraction of water loss from runoff (deep soil drainage plus surface runoff) increased with increasing precipitation.
Sublimation water losses are small with the fraction of water loss as sublimation ranging from $8.4 \%$ at BBR to $3.0 \%$ at KNZ. Theoretically, Good et al. (2017) showed that the fraction of water lost as transpiration increases with increasing precipitation (not shown with our data), that evaporation water loss (bare soil plus interception) increases with increasing aridity and precipitation (consistent with our results), and that runoff increases with increasing precipitation (consistent with our results).

We then computed the correlations of annual ANPP to cumulative precipitation, AET, and $\mathrm{Tr}$ for different time periods (April to May, April to June, April to July, April to August, April to September, and annual) at the 5 sites (Table 3). Results for the two drier sites (CPER and HPGRS) show that the correlation of all three variables to ANPP increases from the cumulative April-to-May period to the cumulative April-toJuly period; for CPER, this increase continues through the April-to-August period for AET and Tr. For these two sites, results from most time periods (Table 3) show that ANPP was most strongly correlated to $\mathrm{Tr}$ and AET, although cumulative precipitation variables tended to have only slightly lower correlation coefficients and sometimes had the highest. Results from both dry sites show that the correlation of ANPP to cumulative precipitation decreased rapidly when extending from the April-to-July to Aprilto-August, as well as longer time periods.

Results from the two Nebraska sites (BBR and GSL, intermediate drought stress) show that the

Table 2. Mean annual precipitation (PPT, cm/yr), aboveground net plant production (ANPP, g biomass $\left.\cdot \mathrm{m}^{-2} \cdot \mathrm{yr}^{-1}\right)$, the ratio between potential evapotranspiration (PET, $\mathrm{cm} / \mathrm{yr}$ ) and PPT, transpiration water loss (Tr, cm/yr), bare soil evaporation water loss (Evap, cm/yr), interception water loss (Intcpt, cm/yr), sublimation water loss (Sublim, cm/yr), and runoff (deep soil drainage plus surface runoff, $\mathrm{cm} / \mathrm{yr}$ ) at the five sites across the precipitation gradient. The long-term average percent of precipitation lost as bare soil evaporation, transpiration, runoff, and plant interception are listed in parentheses. PET, Tr, Evap, Inctp, Sublim, and runoff were simulated by the DayCent model (years 1982-2016).

\begin{tabular}{lcccccccc}
\hline \hline \multicolumn{1}{c}{ Site } & PPT & ANPP & PET/PPT & $\operatorname{Tr}(\% \operatorname{Tr} /$ PPT) & Evap (\%Evap/PPT) & $\begin{array}{c}\text { Intcpt } \\
\text { (\%Intcpt/PPT) }\end{array}$ & $\begin{array}{c}\text { Sublim } \\
\text { (\%Sublim/PPT) }\end{array}$ & $\begin{array}{c}\text { Runoff } \\
(\% \text { runoff/PPT) }\end{array}$ \\
\hline CPER & 38.23 & 72.06 & 2.16 & $18.07(47.26)$ & $12.54(32.80)$ & $4.03(10.54)$ & $1.91(5.01)$ & $1.67(4.37)$ \\
HPGRS & 46.45 & 122.51 & 1.59 & $18.89(47.30)$ & $12.17(30.48)$ & $4.17(10.45)$ & $2.69(6.74)$ & $2.00(5.01)$ \\
BBR & 50.79 & 198.49 & 1.43 & $22.93(45.45)$ & $14.30(28.34)$ & $3.47(6.87)$ & $4.23(8.39)$ & $5.52(10.95)$ \\
GSL & 51.15 & 213.79 & 1.63 & $22.85(44.67)$ & $15.14(29.61)$ & $3.56(6.97)$ & $4.00(7.83)$ & $5.59(10.92)$ \\
KNZ & 83.84 & 385.30 & 0.94 & $36.86(46.65)$ & $13.30(16.83)$ & $4.75(6.02)$ & $2.35(2.98)$ & $21.74(27.51)$ \\
\hline
\end{tabular}

GSL, Gudmundsen Sandhills Laboratory; HPGRS, High Plains Grasslands Research Station. 
correlations for the precipitation-related variables (AET, Tr, and precipitation) all increased when extending from the April-to-May time period with maximum values during the April-toJuly time period. Tr had higher correlations to ANPP, but correlations were similar for AET and precipitation, and there was a gradual drop-off in the correlations of all the variables to ANPP for time periods greater than April to August as observed for the dry HPGRS and CPER sites. The results for the KNZ (the wettest site) show a different pattern where cumulative precipitation was much better correlated to interannual variability in ANPP compared to cumulative $\mathrm{Tr}$ and AET for all of the time periods. We compared the time series of annual ANPP with cumulative April-to-July AET and precipitation for the CPER, and KNZ sites (see Appendix S3: Fig. S4) with the results showing that precipitation and AET had a similar pattern of high annual variability for the CPER site (both well correlated to ANPP), while the results from the KNZ site showed that annual variations in AET were quite small while precipitation had much higher variability and was well correlated to ANPP.

Annual ANPP was strongly correlated with cumulative (May-to-September) AVHRR iNDVI (1-km scale) at the site level (GSL and BBR were combined) using a linear equation for each site and a quadratic function across sites (Fig. 1). The slope of the equations increased with increasing precipitation going from CPER to KNZ (dry to wet sites), while the intercept value decreases with increasing precipitation. The quadratic function showing the relationship between ANPP and iNDVI (higher iNDVI with increasing precipitation) has an $R^{2}$ value equal to 0.90 . We developed a linear equation, which included interactive impact of water stress (ratio of annual cumulative April-to-July AET to cumulative April-to-July PET, i.e., iAET/iPET) on the intercept and slope for the linear regression of iNDVI to $\operatorname{ANPP}$ (Eq. 2).

$$
\begin{aligned}
& A N P P=\operatorname{INTER}\left(\frac{i A E T}{i P E T}\right)+\operatorname{SLOPE}\left(\frac{\text { iAET }}{\text { iPET }}\right) \cdot \text { iNDVI } \\
& \operatorname{INTER}\left(\frac{\text { iAET }}{\text { iPET }}\right)=39.67-465.58 \frac{\text { iAET }}{\text { iPET }} \\
& \operatorname{SLOPE}\left(\frac{\text { iAET }}{\text { iPET }}\right)=43.07+152.04 \frac{\text { iAET }}{\text { iPET }}
\end{aligned}
$$

where INTER(iAET/iPET) is the impact of iAET/ iPET on the intercept, and SLOPE(iAET/iPET) is the impact of iAET/iPET on the slope term. We used the observed site-level annual ANPP, and

Table 3. The correlations (linear regression $R^{2}$ ) of annual aboveground net primary production (ANPP; $g$ biomass $\left.\cdot \mathrm{m}^{-2} \cdot \mathrm{yr}^{-1}\right)$ to three precipitation-related variables, precipitation $(\mathrm{cm})$, transpiration $(\mathrm{cm})$, and actual evap-

\begin{tabular}{|c|c|c|c|c|c|c|c|}
\hline Site & $\begin{array}{l}\text { Precipitation-related } \\
\text { variable }\end{array}$ & Apr-May & Apr-Jun & Apr-Jul & Apr-Aug & Apr-Sep & Annual \\
\hline \multirow[t]{3}{*}{ CPER } & Precipitation & 0.24 & 0.35 & 0.60 & 0.44 & 0.35 & 0.43 \\
\hline & Transpiration & 0.07 & 0.36 & 0.61 & 0.64 & 0.57 & 0.57 \\
\hline & AET & $\overline{0.11}$ & 0.35 & 0.60 & 0.64 & 0.56 & 0.50 \\
\hline \multirow[t]{3}{*}{ HPGRS } & Precipitation & 0.38 & $\underline{0.53}$ & 0.58 & 0.33 & 0.18 & 0.20 \\
\hline & Transpiration & 0.04 & 0.28 & 0.54 & 0.44 & 0.41 & $\underline{0.41}$ \\
\hline & AET & 0.20 & 0.39 & 0.63 & 0.49 & 0.44 & 0.39 \\
\hline \multirow[t]{3}{*}{ BBR/GSL } & Precipitation & 0.44 & 0.63 & 0.69 & 0.59 & 0.53 & 0.53 \\
\hline & Transpiration & 0.37 & 0.60 & 0.70 & 0.60 & $\underline{0.55}$ & $\overline{0.53}$ \\
\hline & AET & 0.33 & 0.56 & 0.66 & 0.56 & 0.48 & 0.47 \\
\hline \multirow[t]{3}{*}{ KNZ } & Precipitation & 0.25 & 0.38 & 0.63 & 0.55 & 0.54 & 0.53 \\
\hline & Transpiration & 0.00 & $\underline{0.00}$ & 0.01 & 0.00 & 0.00 & 0.00 \\
\hline & AET & 0.00 & $\overline{0.00}$ & 0.00 & 0.01 & 0.02 & $\overline{0.02}$ \\
\hline
\end{tabular}
otranspiration (AET, cm) for different time periods (April to May, April to June, April to July, April to August, April to September, and annual (January to December)) at the CPER, HPGRS, BBR, GSL, and KNZ sites.

Notes: ANPP, annual aboveground net primary production; BBR, Barta Brothers Ranch; CPER, Central Plains Experimental Range; GSL, Gudmundsen Sandhills Laboratory; HPGRS, High Plains Grasslands Research Station.

The $R^{2}$ values from low to high are highlighted by five type styles: italics underscore $(<0.10)$, italics $(0.10-0.25)$, regular $(0.25$ $-0.40)$, underscore $(0.40-0.55)$, and bold ( $>0.55)$. The slope term in the regressions was significant $(0.05$ level) for all of the regressions except the correlations of transpiration and AET for the KNZ site. 


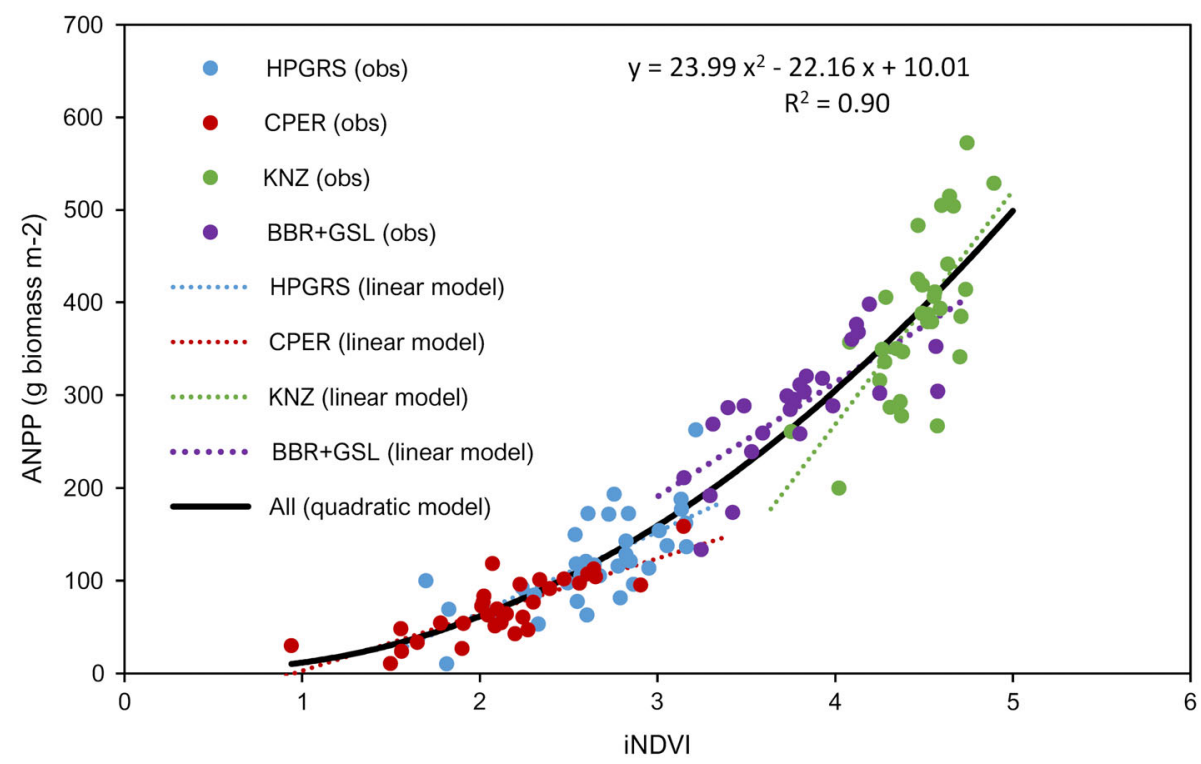

Fig. 1. The correlation of observed annual aboveground net primary production (ANPP) to observed pasturelevel AVHRR iNDVI from the Central Plains Experimental Range (CPER), High Plains Grasslands Research Station (HPGRS), Barta Brothers Ranch (BBR), Gudmundsen Sandhills Laboratory (GSL), and KNZ sites.

iNDVI data to fit the parameters in the equations. The $R^{2}$ values of the correlation between ANPP and iNDVI were both equal to 0.90 either with Eq. 2 or with the quadratic equation of iNDVI. Both equations had similar AIC values (928.7 for Eq. 2 vs. 927.3 for the quadratic equation), and the root mean square errors are similar (44.3 for Eq. 2 vs. 43.6 for the quadratic equation). Either of these functions can be used to predict ANPP as a function of iNDVI in the GP because they used observed ANPP data from sites with low, medium, and high values of precipitation and plant production. Later in the text, we will demonstrate that the ratio of annual cumulative AET to annual cumulative PET is the environmental variable most strongly correlated with annual NRCS county-level ANPP for all of the GP counties.

After establishing that site-level interannual variability in ANPP was well correlated to annual iNDVI (Fig. 1), we investigated how well mean county-level iNDVI can explain spatial variability in ANPP across the region. The county-level NRCS 2004-2014 mean ANPP was also found to be well correlated with county-level mean 19822015 AVHRR iNDVI $\left(R^{2}=0.72\right)$, and the correlation of ANPP to iNDVI is similar for the northern (blue sold circles) and southern (red solid triangles) parts of the GP (Fig. 2) despite C4 grasses dominating the southern GP and C3 grasses the northern GP (Tieszen et al. 1997).

Observed mean annual ANPP for the GP counties based on the mean 2004-2014 NRCS ANPP data showed a strong west to east gradient of increasing ANPP (Fig. 3A) with a tendency for a slight increases in ANPP going northward in the GP. This pattern is similar to the observed pattern in the ratio of the mean April-to-July AET to PET (Fig. 3B) with the ratio increasing going eastward in the GP and increasing slightly going northward in the GP. Correlations of mean annual NRCS ANPP data to environmental variables (AET, precipitation, the ratio of AET to PET, and the ratio of precipitation (PPT) to PET for cumulative April-to-July and annual time periods) show that ANPP is most correlated to the ratio of AET to PET for both time periods $\left(R^{2}=0.68\right.$ for April-to-July AET/ PET vs. 0.58 for April-to-July iAET, $R^{2}=0.70$ for annual AET/PET vs. 0.50 for annual AET). In addition, the correlation with ANPP is higher for the ratio of PPT to PET compared to PPT alone $\left(R^{2}=0.62\right.$ for April-July PPT/PET vs. 0.58 for April-July PPT, $R^{2}=0.68$ for annual PPT/PET vs. 


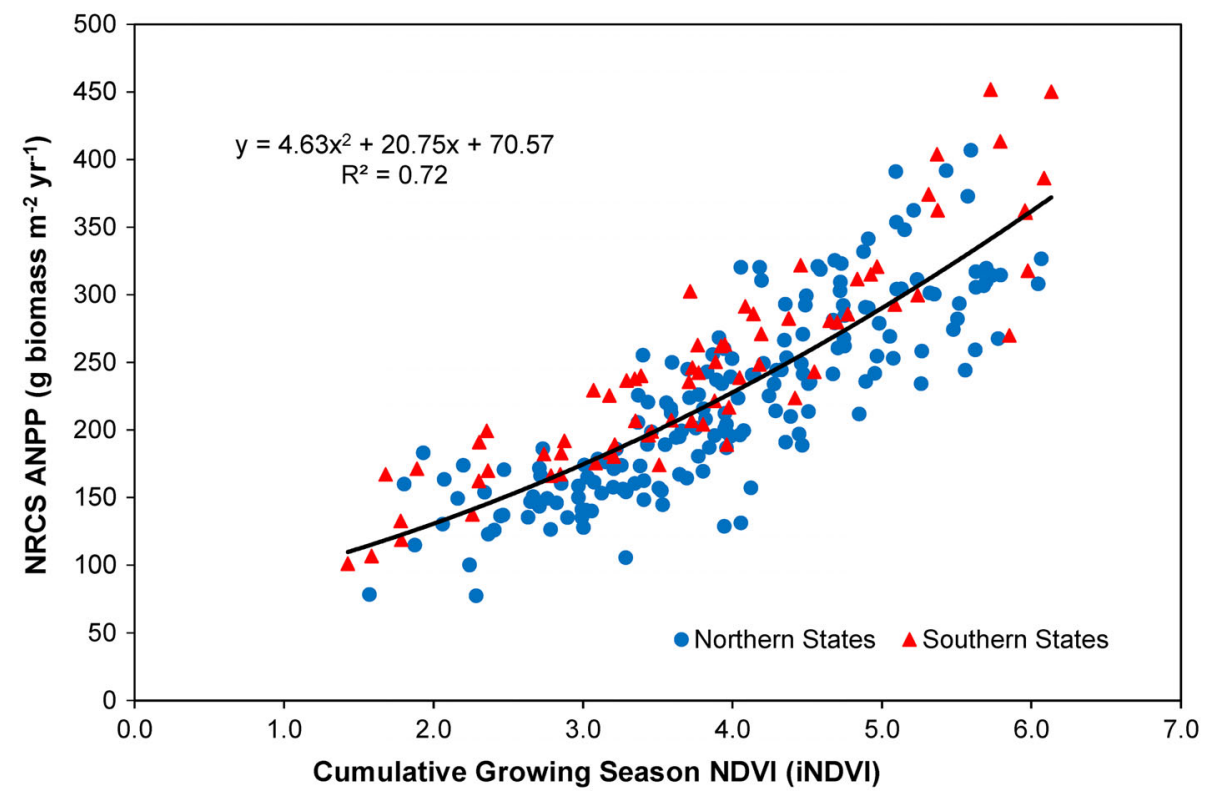

Fig. 2. Correlation of NRCS mean aboveground net primary production (ANPP) to county-level mean iNDVI for all of the Great Plains (GP) counties. Red triangles represent data from the southern GP, while blue dots represent counties in the northern GP.

0.50 for annual PPT). The lower correlation of AET to NRCS mean ANPP compared the ratio of AET to PET occurs because observed AET shows a pattern of decreases in AET going northward from Nebraska to North Dakota (Appendix S4) while observed ANPP increases going northward. The ratio of AET to PET increases going northward from Nebraska to North Dakota (Fig. 3B) because of larger drops in PET rates compared to the decreases in the AET rates (Appendix S4: Figs. S1, S2). The general pattern of decreasing PET rates in the GP causes plant water stress to decrease going northward in the region.

The correlation of yearly (1982-2015) countylevel cumulative April-to-July AET to countylevel iNDVI found that annual changes in iNDVI were well correlated to AET (Fig. 4A) with a mean $R^{2}$ value of 0.47 for all of the GP counties. More than $70 \%$ of the counties have the $R^{2}$ value greater than 0.40 . The majority of the counties with a low $R^{2}$ value $(<0.20)$ occurred in the far eastern part of the GP. We also evaluated the difference between the $R^{2}$ from the correlation of cumulative April-to-July county-level iAET to iNDVI and the $R^{2}$ from the correlation of Aprilto-July precipitation to iNDVI (Fig. $4 \mathrm{~B}, R^{2}$ for AET minus that for precipitation). We found that the correlation was higher for AET compared to precipitation for $>80 \%$ of the counties in the GP with the correlation coefficient related to AET being at least 0.10 greater than the correlation coefficient for precipitation for more than $60 \%$ of the counties. Moreover, the major exception of AET being more highly correlated with ANPP than precipitation was in the southeastern part of Oklahoma. The Oklahoma results are consistent with our results from the KNZ site, which showed much higher correlations of ANPP to precipitation compared to AET and Tr. The likely reason for the low correlation of AET and to iNDVI in Oklahoma is low annual variability in AET as seen at the KNZ site (Appendix S3: Fig. S4) where the larger variability in precipitation was correlated to annual changes in ANPP. We also calculated the correlation of cumulative April-to-July AET and cumulative April-to-July precipitation (Appendix S4: Fig. S3), and coefficient of variation $(\mathrm{CV}$, standard deviation divided by mean) for April-to-July AET and April-to-July precipitation (Appendix S4: Figs. S4, S5) for all of the GP counties. The results showed that AET and precipitation are well correlated $\left(R^{2}>0.70\right)$ for counties in the western part of the GP, while there is a steep decrease in the correlation of AET 
(A) NRCS Estimated 2004-2014 ANPP

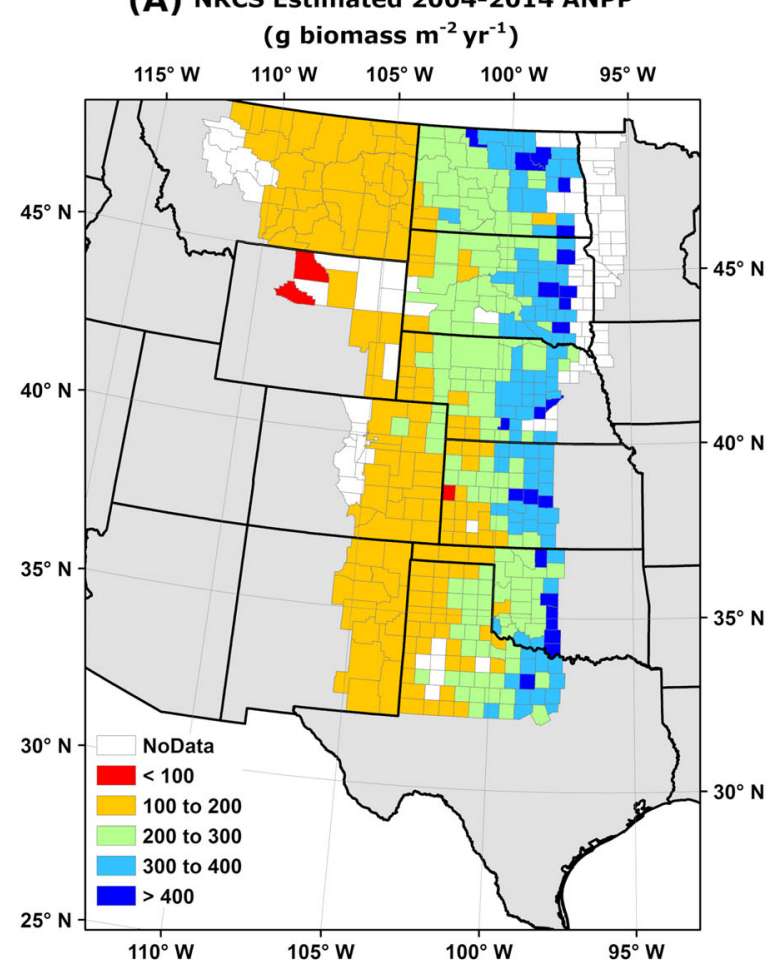

(B) Mean 1982-2015 April-July AET/PET

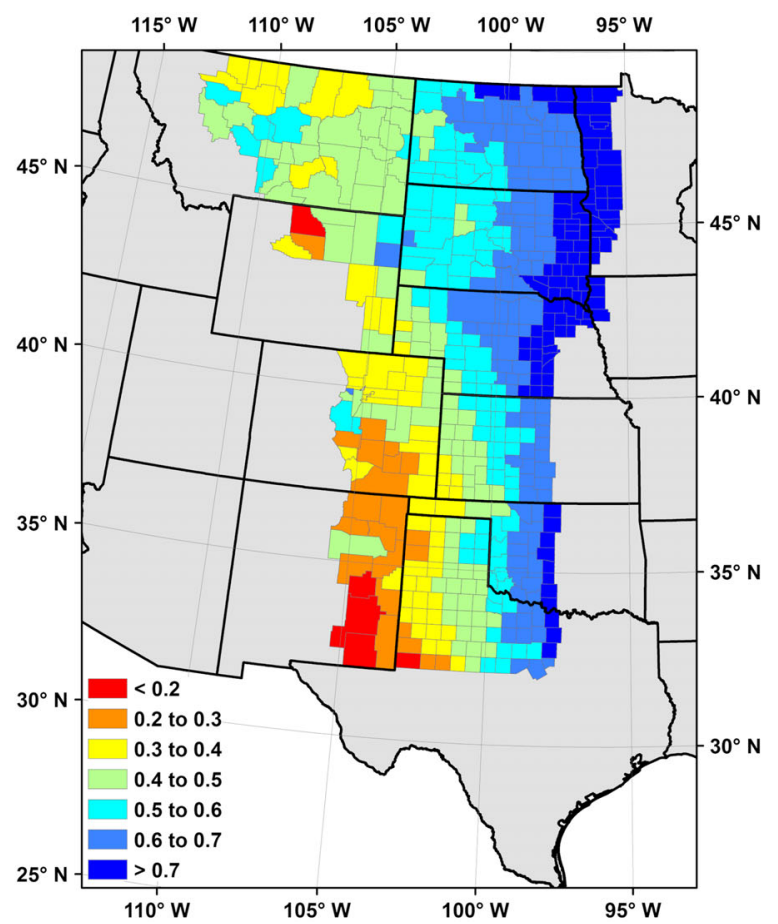

Fig. 3. The spatial distribution of the observed (NRCS) mean annual aboveground net primary production (ANPP) data for the Great Plains (GP) counties between 2004 and 2014 (A). Mean annual ratio of the cumulative April-to-July actual evapotranspiration and potential evapotranspiration (PET) for the Great Plains (GP) counties (B).

to precipitation going eastward in the GP (wet sites) with $R^{2}$ values less than 0.10 for counties in the far eastern part of the GP. The observed patterns show that CV for AET drops off going eastward in the GP with a rapid drop-off in the far eastern part. CV for precipitation also has a general pattern of decreases going eastward in the GP; however, rate of decrease is much less for precipitation compared to AET.

Similar to the analysis performed at the site level, we looked at the impact of the ratio of iAET to iPET for the county-level interannual correlations of iNDVI to both iAET/iPET and iAET. The results showed that the correlation of $\mathrm{iAET} / \mathrm{iPET}$ to iNDVI was slightly stronger than the correlations of iAET to iNDVI, but that the $P$-value for the slope of regressions was not significant ( $P>0.05$ for most counties) for the iAET/iPET regressions, and some slopes were negative. The $P$-values for the slopes were highly significant for the iAET correlations to iNDVI $(P<0.01$ for all counties). A detailed analysis of the results showed that interannual variations in iPET were quite small ( $<15 \%$ of the iPET mean values), while there are large interannual variations in iAET (see Appendix S4: Figs. S4, S5).

Finally, as part of our analysis we determined the impact of another drought index, PDSI, on site-level ANPP in the GP (Dai 2017). We calculated the PDSI at the five ANPP sites and compared the $R^{2}$ values of PDSI to ANPP with the correlation of April-to-July AET to ANPP. The results showed that the PDSI was not well correlated to ANPP with $R^{2}$ values substantially lower (by $20 \%$ to $84 \%$ ) compared to the $R^{2}$ values for the April-to-July AET for CPER, HPGRS, BBR, and GSL. The correlation of precipitation to ANPP for the KNZ site (highest correlated variable - see Table 3) was much higher compared to PDSI index ( $R^{2}$ values $23 \%$ lower for PDSI). 
(A) $R^{2}$ iNDVI vs. IAET 1982-2015

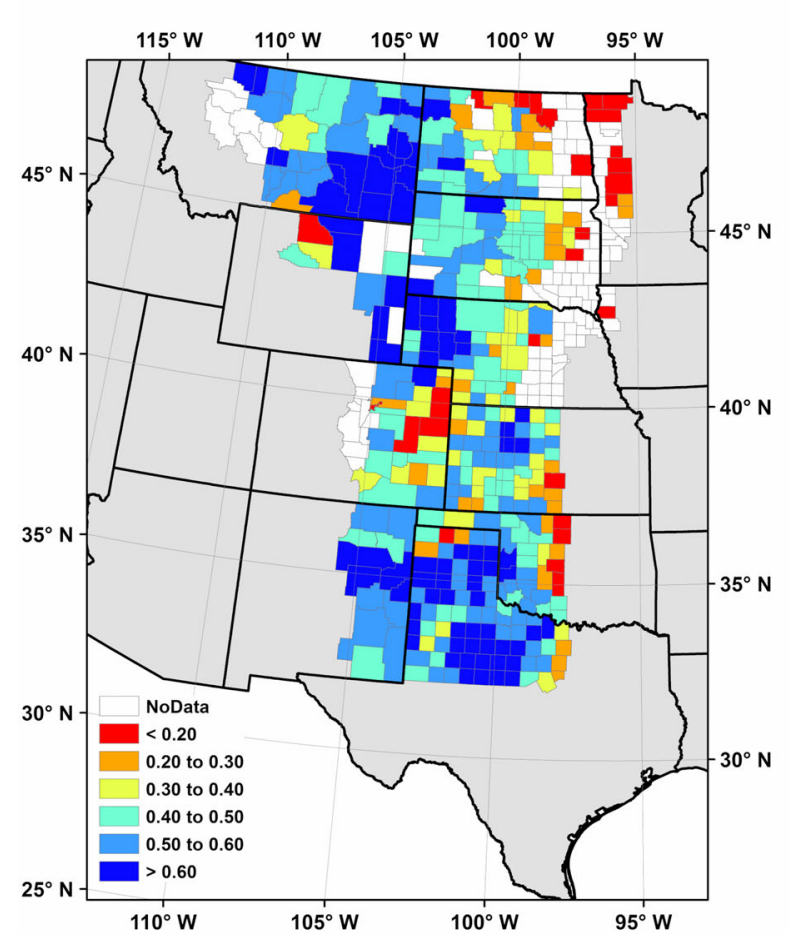

(B) Difference $R^{2}$ iNDVI vs. iAET

and iNDVI vs. iPPT 1982-2015

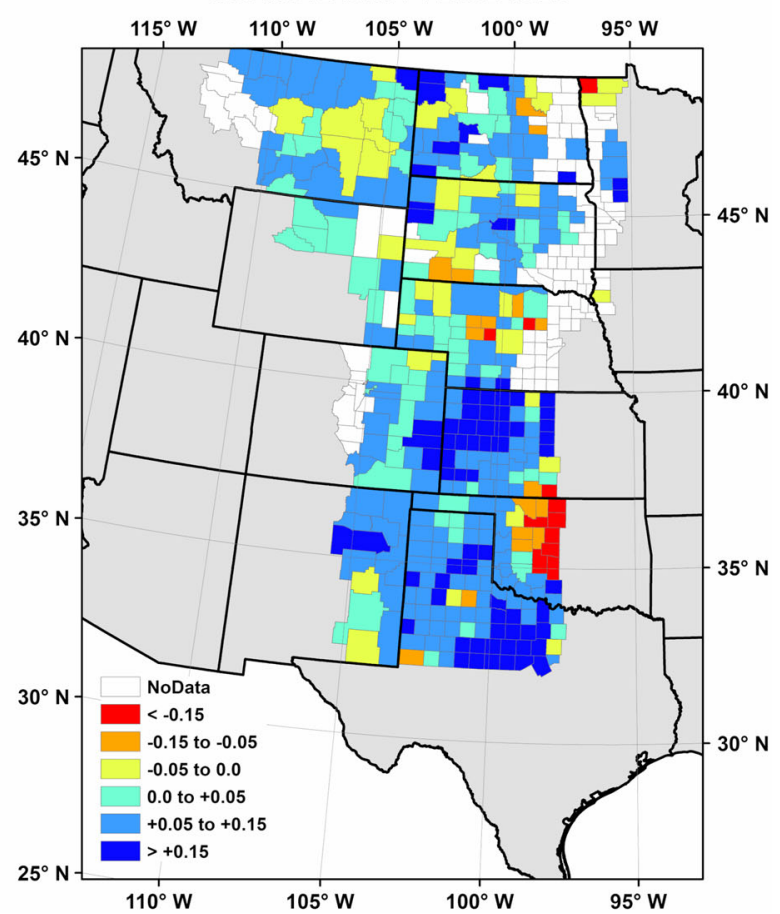

Fig. 4. The spatial distribution of the correlation of county-level seasonal changes in iNDVI to cumulative April April-to-July actual evapotranspiration (AET) (A), and the difference in the correlation coefficients between cumulative April-to-July AET vs. precipitation and annual changes in iNDVI for all of the Great Plains counties (B).

\section{Discussion}

One of the primary goals of this study was to assess the relationships between different precipitation-related variables to spatial and temporal patterns of ANPP across the semiarid and mesic portions of the North American GP. Our results show that mean site-level ANPP was positively correlated to annual precipitation (PPT), plant transpiration (Tr), and cumulative April-to-July AET. The results for the ratio of transpiration to precipitation (Tr/PPT) range from 45 to $47 \%$ for all of our sites and do not change with drought stress or total precipitation. The results show that the fraction of water loss from evaporation (interception plus bare soil water loss) decrease with decreasing water stress and increasing precipitation (from $43 \%$ to $23 \%$ ) and that the fraction of water loss due to runoff (deep drainage and surface runoff) increases from $4 \%$ to $28 \%$ going from the driest site (CPER) to the wettest site (KNZ).
The Tr/AET ratio for the KNZ site is $67 \%$ and near $54 \%$ for the other four sites. Han et al. (2018) reported Tr/AET ratios for the semiarid grassland in northeast of Inner Mongolia, China (59 to 62\%), that were a little greater than those for our four U.S. semiarid sites, but this ratio could drop to $51 \%$ during prolonged drought periods in China. The $\mathrm{Tr} / \mathrm{PPT}$ ratio that we calculated for CPER $(47 \%)$ is similar to those from Lauenroth and Bradford (2006), which showed that the Tr/PPT ratio ranged from $40 \%$ to $75 \%$ on an annual basis with a mean value of $51 \%$ for the CPER site. Our results showing increased evaporation fraction with increased water stress and increased runoff with increased precipitation are consistent with Good et al. (2017); however, Good et al. (2017) suggest that $\mathrm{Tr} / \mathrm{PPT}$ ratio should increase with decreasing water stress (our results show little change in $\mathrm{Tr} /$ PPT with decreasing water stress). Our results show that the $\mathrm{Tr} / \mathrm{AET}$ ratio is highest for the KNZ site ( $67 \%$ vs. $52 \%$ for the other four sites). 
At the site level, annual ANPP and iNDVI from five grassland sites across the precipitation gradient in the GP have a high correlation for a quadratic equation and a linear equation $\left(R^{2}=0.90\right.$ for both equations), which includes the impact the mean iAET/iPET ratio on the slope and intercept. On a broader scale, county-level correlations of ANPP and iNDVI for grasslands in southern and northern GP were also high $\left(R^{2}=0.72\right.$, Fig. 2). Therefore, the correlation of ANPP to iNDVI was similar for the C4-dominated southern GP counties and the C3-dominated northern counties. These results are similar to the results found by Paruelo et al. (1997) and Chen et al. (2017) for grasslands in the GP with a high correlation of iNDVI to ANPP. Similar high correlations have also been found in Africa (Schucknecht et al. 2017), Argentina (Paruelo et al. 2000), and Central Asia (Formica et al. 2017).

We expected that AET would be the best predictor of ANPP across the semiarid and mesic portions of the GP. Our results for dry grassland sites (CPER, HPGRS, BBR, and GSL) show (Table 3) that maximum correlations of annual ANPP occurred for the cumulative April-to-July or April-to-August time periods with the maximum correlations to ANPP mostly occurring for AET and Tr. The results for the semiarid sites (CPER and HPGRS) also showed that there was a large decrease in the correlation coefficient of precipitation to ANPP for time periods after July (approximately 18-42\% decrease), suggesting that August and/or September precipitation is not as effective at promoting grassland plant growth. The results from Hermance et al. (2015) at the CPER site showed that precipitation use efficiency was highest in the spring and decreased rapidly in the summer months (July to September), while Derner and Hart (2007) showed that ANPP at the HPGRS was most correlated with cumulative April-to-June precipitation. These results are also consistent with the grass production (GRASP) Australian grassland model assumption that daily ANPP is directly correlated to plant transpiration (McKeon et al. 1990) and results from Good et al. (2017), suggesting that plant transpiration is one of major factors controlling plant growth.

The results from our site-level comparisons of the precipitation variables that control ANPP and regional correlations of iNDVI to cumulative
April-to-July precipitation and AET show that April-to-July AET variable is typically most correlated to annual changes in ANPP ( $>83 \%$ of the GP counties), while precipitation is more correlated to ANPP for the mesic grassland sites in the southeastern part of the GP (Fig. 4A, B and Table 3). The KNZ site-level analysis and regional analysis of the annual variations in AET (Appendix S3: Fig. S4 and Appendix S4: Fig. S1) suggest that the low correlation of AET to ANPP for the mesic grassland sites results from the low interannual variability of AET at the mesic grassland sites. The correlations of annual changes in cumulative April-to-July AET and precipitation (Appendix S4: Fig. S1) show high correlations of AET to precipitation for the semiarid grassland sites in the western GP $\left(R^{2}>0.70\right)$, while annual changes in AET and precipitation are poorly correlated $\left(R^{2}<0.10\right)$ for the wet grassland sites in the far eastern part of the GP.

Comparison of the impact of water and nutrients on grassland plant production for the CPER (Dodd and Lauenroth 1979) and the tall grass prairie (Owensby et al. 1970) showed that as expected water stress has a great impact on plant production for the dry grasslands, while nutrient availability has a larger impact of plant production for the tall grass site. Chen et al. (2017) showed that there are large interannual changes in cumulative AET and ANPP for the CPER site, while the eddy covariance data (Appendix S3: Figs. S1, S2) show that there are relatively small changes in the seasonal patterns and amount of annual AET at the KNZ site. Another factor that impacts the relative role of water and nutrient stress on plant production is the amount of soil water storage during the winter. There is very little water storage $(<2 \mathrm{~cm}$ on average) during the winter for dry grasslands (Chen et al. 2017), while soil water storage at the KNZ site is $>4 \mathrm{~cm}$ per year. Risser (1981) showed that winter non-growing season precipitation is higher for KNZ compared to CPER and Briggs and Knapp (1995) show that soil moisture tends to be maximal in the late winter/early spring at KNZ. It is unclear why annual changes of ANPP are well correlated to cumulative April-to-July changes in precipitation for the mesic grasslands; however, it is possible that changes in precipitation are correlated to changes in nutrients available for plant growth (primarily nitrogen). The 
potential for annual variations in nitrogen availability to control yearly changes in ANPP is supported by results from the Owensby et al. (1970) irrigation and nitrogen addition studies for a site near the KNZ site, which showed that nitrogen additions have a bigger impact on ANPP compared to irrigation.

NRCS county-level observations of ANPP show a strong decrease in ANPP going westward across the GP, consistent with results from the Sala et al. (1988) for the GP; however, Sala et al. (1988) show a pattern of decreasing ANPP going northward in the GP (opposite of our results). The reason for this discrepancy is not clear; however, we used county-level ANPP estimate, while the Sala et al. (1988) used state-level Major Land Resource Areas average ANPP data. Our countylevel ANPP analysis uses a much fine spatial scale ( $>5$-time finer spatial scale), which should be better able to represent the spatial patterns in ANPP. Sala et al. (1988) assessed the impact of annual precipitation on ANPP in the GP, while our results show that the ratio of annual AET to PET is the best correlated variable to spatial patterns of mean NRCS ANPP in the GP. The ratio of AET to PET and the observed mean ANPP results show a general pattern of slight increases in ANPP going northward in the GP, while the observed precipitation and April-to-July AET data both show a pattern of decreasing precipitation and AET going northward from Nebraska to North Dakota.

A summary of the results shows that at the site level the cumulative April-to-July AET is a good indicator of the annual changes of ANPP, and at the regional scale, AET is also the major factor controlling spatial ANPP patterns (for $>83 \%$ of the GP counties) with a strong pattern of decreasing AET and ANPP going westward across the GP. The cumulative April-to-July AET is also well correlated to iNDVI, and iNDVI can be used to estimate ANPP. Results from the mesic grassland sites (see Appendix S3: Fig. S4) show that April-to-July precipitation is better correlated with ANPP because of the low interannual variability of AET for the mesic grassland sites.

Six major conclusions can be drawn from this work: (1) Interannual variability in site-level ANPP was correlated better to AET than precipitation at all but the most mesic site considered; (2) interannual variability of site-level ANPP is well correlated with cumulative May-to-September NDVI (iNDVI), and this relationship can be expressed as a function of the ratio of Aprilto-July AET to April-to-July PET; (3) spatial patterns in mean ANPP at the county-level are highly correlated with iNDVI; (4) interannual variability in county-level iNDVI is correlated better to AET than precipitation in the majority of counties across the GP with most of the exceptions located in the mesic eastern portion of the region where precipitation is more variable than AET; (5) growing season accumulations of precipitation-related variables, such as AET and Tr, have stronger correlations to iNDVI and ANPP than annual values do at both the site and county levels; and (6) that the April-to-July AET/PET drought index was the variable most correlated to mean county-level ANPP.

Different precipitation-related variables controlling ANPP across the drier portions of the GP (cumulative April-to-July AET) to more mesic portions of the GP (cumulative April-July precipitation) provide opportunities to develop spatially explicit forecasting of ANPP for enhancing decision-making by land managers and use for biofuel grassland plant production. County-level correlations of AET to iNDVI and the correlation of iNDVI to ANPP are currently being used by the Grass-Cast model (http://grasscast.agsci.c olostate.edu/) to predict ANPP for all of the GP counties on a biweekly basis starting from the middle of April to the end of July. Results in this paper suggest that using precipitation instead of AET for the eastern counties would improve model predictions.

\section{ACKNOWLEDGMENTS}

This work is supported by the US Department of Agriculture (USDA) UV-B Monitoring and Research Program, Colorado State University, under USDA National Institute of Food and Agriculture Grant 201634263-25763. This work is partially supported by the DOE Center for Advanced Bioenergy and Bioproducts Innovation (U.S. Department of Energy, Office of Science, Office of Biological and Environmental Research under Award Number DE-SC0018420). This research is also partially supported by funds from USDA Grass-Cast and DayCent modeling Coop agreements (58-3012-7-009 and 58-5402-4-011) and the University of Nebraska USDA Grass-Cast project (580111-18-018). 


\section{Literature Cited}

An, N., K. P. Price, and J. M. Blair. 2013. Estimating above-ground net primary productivity of the tallgrass prairie ecosystem of the Central Great Plains using AVHRR NDVI. International Journal of Remote Sensing 34:3717-3735.

Asner, G. P., A. J. Elmore, L. P. Olander, R. E. Martin, and A. T. Harris. 2004. Grazing systems, ecosystem responses, and global change. Annual Review of Environment and Resources 29:261-299.

Briggs, J. M., and A. K. Knapp. 1995. Interannual variability in primary production in tallgrass prairie: climate, soil moisture, topographic position, and fire as determinants of aboveground biomass. American Journal of Botany 82:1024 1030.

Chen, M., W. J. Parton, E. C. Adair, S. Asao, M. D. Hartman, and W. Gao. 2016. Simulation of the effects of photodecay on long-term litter decay using DayCent. Ecosphere 7:e01631-1-e01631-22.

Chen, M., et al. 2017. The signature of sea surface temperature anomalies on the dynamics of semiarid grassland productivity. Ecosphere 8:e02069-1e02069-14.

Dai, A. 2017. Dai Global Palmer Drought Severity Index (PDSI). Research Data Archive at the National Center for Atmospheric Research, Computational and Information Systems Laboratory. https://doi.org/10.5065/d6qf8r93

Day, K. A., G. M. McKeon, and D. M. Orr. 1993. Comparison of Methods for assessing productivity of native pastures in Queensland. Pages 784-785 in I. G. Congress, editor. Proceeding of the XVII International Grassland Congress. New Zealand Grassland Association, Palmerston North, New Zealand.

Del Grosso, S. J., H. T. Gollany, and M. Reyes-Fox. 2016. Simulating soil organic carbon stock changes in agroecosystems using CQESTR, DayCent, and IPCC Tier 1 methods. Pages $89-110$ in S. Del Grosso, L. Ahuja, and W. Parton, editors. Synthesis and modeling of greenhouse gas emissions and carbon storage in agricultural and forest systems to guide mitigation and adaptation. American Society of Agronomy, Crop Science Society of America, and Soil Science Society of America, Madison, Wisconsin, USA.

Del Grosso, S. J., W. J. Parton, J. D. Derner, M. Chen, and C. J. Tucker. 2018. Simple models to predict grassland ecosystem $C$ exchange and actual evapotranspiration using NDVI and environmental variables. Agricultural and Forest Meteorology 249: $1-10$.

Del Grosso, S. J., W. J. Parton, C. A. Keough, and M. Reyes-Fox. 2011. Special features of the DayCent modeling package and additional procedures for parameterization, calibration, validation, and applications. Pages 155-176 in L. R. Ahuja and L. Ma, editors. Methods of introducing system models into agricultural research. American Society of Agronomy, Madison, Wisconsin, USA.

Del Grosso, S. J., W. J. Parton, A. R. Mosier, M. D. Hartman, J. Brenner, D. S. Ojima, and D. S. Schimel. 2001. Simulated interaction of carbon dynamics and nitrogen trace gas fluxes using the DAYCENT model. Pages 303-332 in M. J. Schaffer, L. Ma, and S. Hansen, editors. Modeling carbon and nitrogen dynamics for soil management. CRC Press, Boca Raton, Florida, USA.

Del Grosso, S., W. Parton, T. Stohlgren, D. Zheng, D. Bachelet, S. Prince, K. Hibbard, and R. Olson. 2008. Global potential net primary production predicted from vegetation class, precipitation, and temperature. Ecology 89:2117-2126.

Derner, J. D., and R. H. Hart. 2007. Grazing-induced modifications to peak standing crop in northern mixed-grass prairie. Rangeland Ecology \& Management 60:270-276.

Dodd, J. L., and W. K. Lauenroth. 1979. Analysis of the response of a grassland ecosystem to stress. Pages 43-58 in N. R. French, editor. Perspectives in grassland ecology: results and applications of the US/ IBP grassland biome study. Springer New York, New York, New York, USA.

Epstein, H. E., W. K. Lauenroth, and I. C. Burke. 1997. Effects of temperature and soil texture on ANPP in the U.S. great plains. Ecology 78:2628-2631.

Formica, A. F., R. J. Burnside, and P. M. Dolman. 2017. Rainfall validates MODIS-derived NDVI as an index of spatio-temporal variation in green biomass across non-montane semi-arid and arid Central Asia. Journal of Arid Environments 142: 11-21.

Friedl, M. A., D. Sulla-Menashe, B. Tan, A. Schneider, N. Ramankutty, A. Sibley, and X. Huang. 2010. MODIS collection 5 global land cover: algorithm refinements and characterization of new datasets. Remote Sensing of Environment 114:168-182.

Gilmanov, T. G., L. L. Tieszen, B. K. Wylie, L. B. Flanagan, A. B. Frank, M. R. Haferkamp, T. P. Meyers, and J. A. Morgan. 2005. Integration of CO2 flux and remotely-sensed data for primary production and ecosystem respiration analyses in the Northern Great Plains: potential for quantitative spatial extrapolation. Global Ecology and Biogeography 14:271-292.

Good, S. P., G. W. Moore, and D. G. Miralles. 2017. A mesic maximum in biological water use demarcates biome sensitivity to aridity shifts. Nature Ecology \& Evolution 1:1883-1888. 
Han, D., G. Wang, T. Liu, B.-L. Xue, G. Kuczera, and X. Xu. 2018. Hydroclimatic response of evapotranspiration partitioning to prolonged droughts in semiarid grassland. Journal of Hydrology 563:766-777.

Hartman, M. D., E. R. Merchant, W. J. Parton, M. P. Gutmann, S. M. Lutz, and S. A. Williams. 2011. Impact of historical land-use changes on greenhouse gas exchange in the U.S. Great Plains, 18832003. Ecological Applications 21:1105-1119.

Hendrickson, J. R., L. E. Moser, and P. E. Reece. 2000. Tiller recruitment patterns and biennial tiller production in prairie sandreed. Journal of Range Management 53:537-543.

Hermance, J. F., D. J. Augustine, and J. D. Derner. 2015. Quantifying characteristic growth dynamics in a semi-arid grassland ecosystem by predicting shortterm NDVI phenology from daily rainfall: a simple four parameter coupled-reservoir model. International Journal of Remote Sensing 36:5637-5663.

IPCC. 2013. Climate Change 2013: The Physical Science Basis. Contribution of Working Group I to the Fifth Assessment Report of the Intergovernmental Panel on Climate Change. Cambridge University Press, Cambridge, UK and New York, New York, USA.

Irisarri, J. G. N., M. Oesterheld, J. M. Paruelo, and M. A. Texeira. 2012. Patterns and controls of aboveground net primary production in meadows of Patagonia. A remote sensing approach. Journal of Vegetation Science 23:114-126.

Knapp, A. K., J. M. Briggs, D. C. Hartnett, and S. L. Collins. 1998. Grassland dynamics: long-term ecological research in tallgrass prairie. Oxford University Press, New York, New York, USA.

Knapp, A. K., and M. D. Smith. 2001. Variation among biomes in temporal dynamics of aboveground primary production. Science 291:481-484.

Lauenroth, W. K. 1979. Grassland primary production: North American grasslands in perspective. Pages 3-24 in N. R. French, editor. Volume 32 of the series ecological studies. Perspectives in grassland ecology. Springer-Verlag, New York, New York, USA.

Lauenroth, W. K. 2013. SGS-LTER Standard Production Data: 1983-2008 Annual Aboveground Net Primary Production on the Central Plains Experimental Range, Nunn, Colorado, USA 1983-2008, ARS Study Number 6. http://hdl.handle.net/10217/81141

Lauenroth, W. K., and J. B. Bradford. 2006. Ecohydrology and the partitioning AET between transpiration and evaporation in a semiarid steppe. Ecosystems 9:756-767.

Lauenroth, W. K., J. L. Dodd, and P. L. Sims. 1978. The effects of water- and nitrogen-induced stresses on plant community structure in a semiarid grassland. Oecologia 36:211-222.
Lauenroth, W. K., and O. E. Sala. 1992. Long-term forage production of North American shortgrass steppe. Ecological Applications 2:397-403.

Li, X., G. Chen, X. Liu, X. Liang, S. Wang, Y. Chen, F. Pei, and X. Xu. 2017. A new global land-use and land-cover change product at a 1-km resolution for 2010 to 2100 based on human-environment interactions. Annals of the American Association of Geographers 107:1040-1059.

McKeon, G. M., K. A. Day, S. M. Howden, J. J. Mott, D. M. Orr, W. J. Scattini, and E. J. Weston. 1990. Northern Australian Savannas: management for Pastoral Production. Journal of Biogeography 17:355-372.

Melzer, S. E., A. K. Knapp, K. P. Kirkman, M. D. Smith, J. M. Blair, and E. F. Kelly. 2010. Fire and grazing impacts on silica production and storage in grass dominated ecosystems. Biogeochemistry 97:263278.

Morgan, J. A., W. Parton, J. D. Derner, T. G. Gilmanov, and D. P. Smith. 2016. Importance of early season conditions and grazing on carbon dioxide fluxes in Colorado shortgrass steppe. Rangeland Ecology \& Management 69:342-350.

Mowll, W., D. M. Blumenthal, K. Cherwin, A. Smith, A. J. Symstad, L. T. Vermeire, S. L. Collins, M. D. Smith, and A. K. Knapp. 2015. Climatic controls of aboveground net primary production in semiarid grasslands along a latitudinal gradient portend low sensitivity to warming. Oecologia 177: 959-969.

National Oceanic and Atmospheric Administration NOAA. 1992. AVHRR (Advanced Very High Resolution Radiometer) Composites, NASA EOSDIS Land Processes DAAC, USGS Earth Resources Observation and Science (EROS) Center, Sioux Falls, South Dakota. https://doi.org/10.5066/f77 07zkn

Owensby, C. E., M. H. Robert, and K. L. Anderson. 1970. Effects of clipping and supplemental nitrogen and water on loamy upland bluestem range. Journal of Range Management 23:341-346.

Parton, W. J., M. P. Gutmann, E. R. Merchant, M. D. Hartman, P. R. Adler, F. M. McNeal, and S. M. Lutz. 2015. Measuring and mitigating agricultural greenhouse gas production in the US Great Plains, 1870-2000. Proceedings of the National Academy of Sciences of the United States of America 112: E4681-E4688.

Parton, W. J., M. Hartman, D. Ojima, and D. Schimel. 1998. DAYCENT and its land surface submodel: description and testing. Global and Planetary Change 19:35-48.

Parton, W., J. Morgan, D. Smith, S. Del Grosso, L. Prihodko, D. LeCain, R. Kelly, and S. Lutz. 2012. 
Impact of precipitation dynamics on net ecosystem productivity. Global Change Biology 18:915-927.

Paruelo, J. M., H. E. Epstein, W. K. Lauenroth, and I. C. Burke. 1997. ANPP estimates from NDVI for the central grassland region of the United States. Ecology 78:953-958.

Paruelo, J. M., M. Oesterheld, C. M. Di Bella, M. Arzadum, J. Lafontaine, M. Cahuepé, and C. M. Rebella. 2000. Estimation of primary production of subhumid rangelands from remote sensing data. Applied Vegetation Science 3:189-195.

Petrie, M. D., et al. 2018. Regional grassland productivity responses to precipitation during multiyear above- and below-average rainfall periods. Global Change Biology 24:1935-1951.

Pinzon, J., and C. Tucker. 2014. A non-stationary 19812012 AVHRR NDVI $_{3}$ g time series. Remote Sensing 6:6929-6960.

Risser, P. G. 1981. The true prairie ecosystem. Hutchinson Ross Pub., Stroudsburg, Pennsylvania, USA.

Sala, O. E., W. J. Parton, L. A. Joyce, and W. K. Lauenroth. 1988. Primary production of the central grassland region of the United States. Ecology 69:40-45.

Schacht, W. H., J. D. Volesky, D. Bauer, A. Smart, and E. Mousel. 2000. Plant community patterns on upland prairie in the eastern Nebraska sandhills. Agronomy-Faculty Publications 339.

Schucknecht, A., M. Meroni, F. Kayitakire, and A. Boureima. 2017. Phenology-based biomass estimation to support rangeland management in semiarid environments. Remote Sensing 9:463.

Straube, J. R., M. Chen, W. J. Parton, S. Asso, Y.-A. Liu, D. S. Ojima, and W. J. F. O. E. S. Gao. 2018. Development of the DayCent-Photo model and integration of variable photosynthetic capacity. Frontiers of Earth Science, 12:765-778.

Tieszen, L. L., B. C. Reed, N. B. Bliss, B. K. Wylie, and D. D. DeJong. 1997. NDVI, C3 and C4 production, and distributions in great plains grassland land cover classes. Ecological Applications, 7:59-78.

Tucker, C. J. 1979. Red and photographic infrared linear combinations for monitoring vegetation. Remote Sensing of Environment 8:127-150.

USDA-Natural Resources Conservation Service USDA-NRCS. 2018. National Resource Inventory Rangeland Field Study. USDA-NRCS Resource Inventory Division, Wash. D.C. Iowa State University Center for Survey Statistics and Methodology, Ames, Iowa, USA. https://www.nrcs.usda.gov/ wps/portal/nrcs/detail/national/technical/nra/nri/ results/?cid=nrcseprd1343025

Volesky, J. D., W. H. Schacht, P. E. Reece, and T. J. Vaughn. 2005. Spring growth and use of cool-season graminoids in the Nebraska sandhills. Rangeland Ecology \& Management 58:385-392.

Wilcox, K. R., J. M. Blair, M. D. Smith, and A. K. Knapp. 2016. Does ecosystem sensitivity to precipitation at the site-level conform to regional-scale predictions? Ecology 97:561-568.

Yonker, C. M., D. S. Schimel, E. Paroussis, and R. D. Heil. 1988. Patterns of organic carbon accumulation in a semiarid shortgrass steppe, Colorado. Soil Science Society of America Journal 52:478-483.

Zelikova, T. J., D. M. Blumenthal, D. G. Williams, L. Souza, D. R. LeCain, J. Morgan, and E. Pendall. 2014. Long-term exposure to elevated $\mathrm{CO} 2$ enhances plant community stability by suppressing dominant plant species in a mixed-grass prairie. Proceedings of the National Academy of Sciences of the United States of America 111:15456-15461.

Zhang, L., B. K. Wylie, L. Ji, T. G. Gilmanov, and L. L. Tieszen. 2010. Climate-driven interannual variability in net ecosystem exchange in the northern great plains grasslands. Rangeland Ecology \& Management 63:40-50.

\section{SUPPORTING INFORMATION}

Additional Supporting Information may be found online at: http://onlinelibrary.wiley.com/doi/10.1002/ecs2. 2889/full

Appendix S1: Outlier analysis for GSL and BBR NDVI and ANPP data

Appendix S2: Average 2004-2014 NRCS ANPP for the U.S. GP counties

Appendix S3: Comparison of simulated and observed water variables and their correlations with ANPP observations at the site level

Appendix S4: Additional regional distributions of water variables and their correlations in the U.S. GP 